\title{
ANÁLISE DA RELAÇÃO OFERTA / DEMANDA E QUALIDADE DA ÁGUA NO MUNICÍPIO DE UBÁ-MG
}

\author{
Daiani Aparecida Gomes Teixeira ${ }^{1}$ \\ Scarlet Santos Monteiro ${ }^{2}$ \\ Fabrício Oliveira Ramos ${ }^{3}$
}

Resumo: A oferta de água para consumo vem diminuindo com a falta de preocupação do ser humano na preservação. Ubá está localizado na zona da mata mineira e tem aproximadamente 101.519 habitantes, e vem passando por sérios problemas com falta de água na estiagem. Este fato aumentou a perfuração de poços semi-artesianos pela população. O objetivo foi analisar amostras de água coletadas em quatro bairros diferentes, a fim de verificar a qualidade da água oferecida para consumo comparado aos valores préestabelecidos pela Portaria No 2.914/2011 do Ministério da Saúde. As análises ocorreram na UEMG-Ubá, nos laboratórios de química e LANAG, foram coletadas um total de 23 amostras, sendo 12 de poços e 11 da COPASA, foram quantificadas em cada amostra a temperatura, $\mathrm{pH}$, turbidez, sólidos totais, dureza total, cloreto, nitrato e coliformes totais. Os resultados das análises demonstram oscilação nos valores encontrados e excedendo o padrão exigido.

Palavras-chave: Água; Poço semi-artesiano; Análise.

Departamento de Biologia/Universidade do Estado de Minas Gerais, Brasil. E-mail: daiani_teixeira@hotmail.com.

2 Departamento de Biologia/Universidade do Estado de Minas Gerais, Brasil. E-mail: scarletsantosm@gmail.com.

${ }^{3}$ Departamento de Biologia/Universidade do Estado de Minas Gerais, Brasil. E-mail: ramosfo@yahoo.com.br. 